\title{
Multiscale Spatio-Temporal Dynamics of Economic Development in an Interprovincial Boundary Region: Junction Area of Tibetan Plateau, Hengduan Mountain, Yungui Plateau and Sichuan Basin, Southwestern China Case
}

\author{
Jifei Zhang ${ }^{1,2}$ and Wei Deng ${ }^{1, *}$ \\ 1 Institute of Mountain Hazards and Environment, Chinese Academy of Sciences, Chengdu 610041, China; \\ jfzhang@imde.ac.cn \\ 2 The International Centre for Integrated Mountain Development, Kathmandu 44700, Nepal \\ * Correspondence: dengwei@imde.ac.cn; Tel./Fax: +86-028-8535-3897
}

Academic Editors: Giuseppe Ioppolo and Marc A. Rosen

Received: 8 December 2015; Accepted: 25 February 2016; Published: 29 February 2016

\begin{abstract}
An interprovincial boundary region is a new subject of economic disparity study in China. This study explored the multi-scale spatio-temporal dynamics of economic development from 1995 to 2010 in the interprovincial boundary region of Sichuan-Yunnan-Guizhou, a mountain area and also the junction area of Tibetan Plateau, Hengduan Mountain, Yungui Plateau and Sichuan Basin in southwestern China. A quantitative study on county GDP per capita for different scales of administrative regions was conducted using the Theil index, Markov chains, a geographic information system and exploratory spatial data analysis. Results indicated that the economic disparity was closely related with geographical unit scale in the study area: the smaller the unit, the bigger the disparity, and the regional inequality gradually weakened over time. Moreover, significant positive spatial autocorrelation and clustering of economic development were also found. The spatial pattern of economic development presented approximate circle structure with two cores in the southwest and northeast. The Panxi region in the southwest core and a part of Hilly Sichuan Basin in the northeast core were considered to be hot spots of economic development. Most areas in the east and central region were persistently trapped in the low level of a balanced development state, with a poverty trap being formed in the central and south part. Geographical conditions and location, administrative barriers and the lack of effective growth poles may be the main reasons for the entire low level of balanced development. Our findings suggest that in order to achieve a high level of balanced development, attention should be paid beyond developing transportation and other infrastructure. Breaking down the rigid shackles of administrative districts that hinder trans-provincial cooperation and promoting new regional poles in the Yunnan-Guizhou region may have great significance for the study area.
\end{abstract}

Keywords: multiscale; spatio-temporal dynamics; economic development; interprovincial boundary region; junction area of Tibetan Plateau; Hengduan Mountain; Yungui Plateau and Sichuan Basin; southwestern China

\section{Introduction}

Owning to breakneck economic growth over the past three decades, China has become the world's second largest economy [1], and is predicted to catch up with the US within 10 years. One needs to recognize that this economic achievement, however, has not been shared fairly across China's different 
regions [2-4]. The regional economic inequality of China has been an issue of great importance for politicians and regional scientists [5-7]. Many studies draw lessons from the quantitative methods of economics, using models to reveal the spatial distribution of socioeconomic phenomena in China and other countries, such as the coefficient of variation [8,9], Gini coefficient [10,11], generalized entropy index [12], Theil index [13,14], Ellison-Glaeser index [15,16], Wolfson index [17], Tusi-Wang index [18], Kanbur-Zhang Index [19] and convergence model [20]. However, the mentioned models can hardly truly reflect the variation and mechanism of regional spatial disparity. They also have some shortcomings in assessing the spatial structure and evolution of regional economies due to the lack of a spatial econometric perspective and their ignoring of spatial autocorrelations as well as spatial heterogeneity [21,22].

With spatial thinking attracting increasing attention [23-27], spatial convergence and divergence of regional economic growth has become a new subject in economic geography. Researchers have conducted studies of the constantly expanding spatial differentiation and agglomeration of European and North American countries [28-30]. Based on reflecting on spatial correlation and using spatial autocorrelation, exploratory spatial data analysis (ESDA) has been considered to be an innovative quantitative method and a significant tool to investigate economic growth patterns and regional spatial disparities [31]. Many significant results have been achieved by ESDA [32-34]. However, China's current research on regional economic differences presents two limitations. First, developed regions attract much more attention [35-38]. Second, large-scale and mesoscale regions are more likely to be involved, such as state-level regions [39,40], the eastern, the middle and the western regions [24,41], the southern and the northern regions [42], province-level [43-45] and city-level regions [46].

Thus, by and large, the economic disparities of underdeveloped regions and small-scale regions, as well as multiscale research, have not received sufficient attention. For instance, mountain areas and interprovincial boundary regions (IBR) have rarely been mentioned. An IBR is a specific geographical region composed of the juncture of two or more provinces [47]. In China, 849 counties (or cities), accounting for $39 \%$ of the county-level administrative regions of the country, are distributed along the two sides of $5200 \mathrm{~km}$ provincial land administrative boundary line [48]. Because they are far away from provincial centers and the administrative boundary limits the diffusion of economic activities, almost every IBR in China has consistently been a marginal region of investment and economic development even in the market economy period [49]. Moreover, analyzing the economic disparity of small-scale [50] and multi-scale regions is considered to be helpful in approaching the regional development reality and benefit to find the driving forces behind. Mountains of southwest China (Sichuan, Yunan and Guizhou Province) are one of the country's most important mountain areas because of natural resources. The IBR of Sichuan-Yunnan-Guizhou (IBRS) is the mineral resource core of mountains of southwest China. Moreover, as the "Western Development Strategy" entering into the promotion stage and the Yangtze River Economic Belt (YREB) Development Strategy was promoted [51,52], the IBRS has become one of the most dynamic and high-focus regions in China. Being both mountains and IBR, the IBRS has to be faced with tremendous pressure of economic development.

The main purpose of the present article is to explore the multiscale spatio-temporal dynamics of economic development of the IBRS during the past 16 years, discuss the major causes of development and underdevelopment and provide policy recommendations to assist this region towards a high level of balanced economy. To achieve this purpose, the Theil index model, Markov chain model, GIS and ESDA analysis are used based on GDP per capita data at the county level from 1995-2010.

\section{Materials and Methods}

\subsection{Study Area}

The IBRS is located in the transition zone connecting the first topographic step and the second topographic step of China, and is also the junction of Tibetan Plateau, Hengduan Mountain, Yungui Plateau and Sichuan Basin [53] $\left(25^{\circ} 2^{\prime} \mathrm{N}-29^{\circ} 20^{\prime} \mathrm{N}, 100^{\circ} 3^{\prime} \mathrm{E}-106^{\circ} 44^{\prime} \mathrm{E}\right)$ (Figure 1). It includes 
75 county-level administrative regions, belonging to 13 cities of three provinces (Table 1). Situated in the upper reaches of Yangtze River, the IBRS has complex natural conditions and fragile ecological environment with mountain and plateau covering more than $80 \%$ of its area. Hence, the IBRS is a crucial region for conserving water in the upper reaches of Yangtze River, as well as an important part of ecological shelter zone of Yangtze River [54]. As a multi-ethnic and well known Yi nationality inhabited region, the IBRS is a typical underdeveloped region [53]. In 2010, its GDP only accounted for $1.29 \%$ of that of China with a population of $2.78 \%$ and an area of $2.01 \%$ of the whole country. In the same year, the GDP per capital of the IBRS $(\$ 2,086)$ was even less than one-half of that of the country $(\$ 4,479)$. At county level in 2010, the highest GDP per capital $(\$ 9,987$; in East District of Panzhihua City) was 17 times that of the lowest one (\$585; in Zhenxiong County of Zhaotong City). Furthermore, counties inside the IBRS show extensive homogeneity in geographical conditions, natural resources, culture background and industrial structure. As a famous resource-rich region of China, and due to its special geographical location, the IBRS's economic development is attracting much attention nowadays.

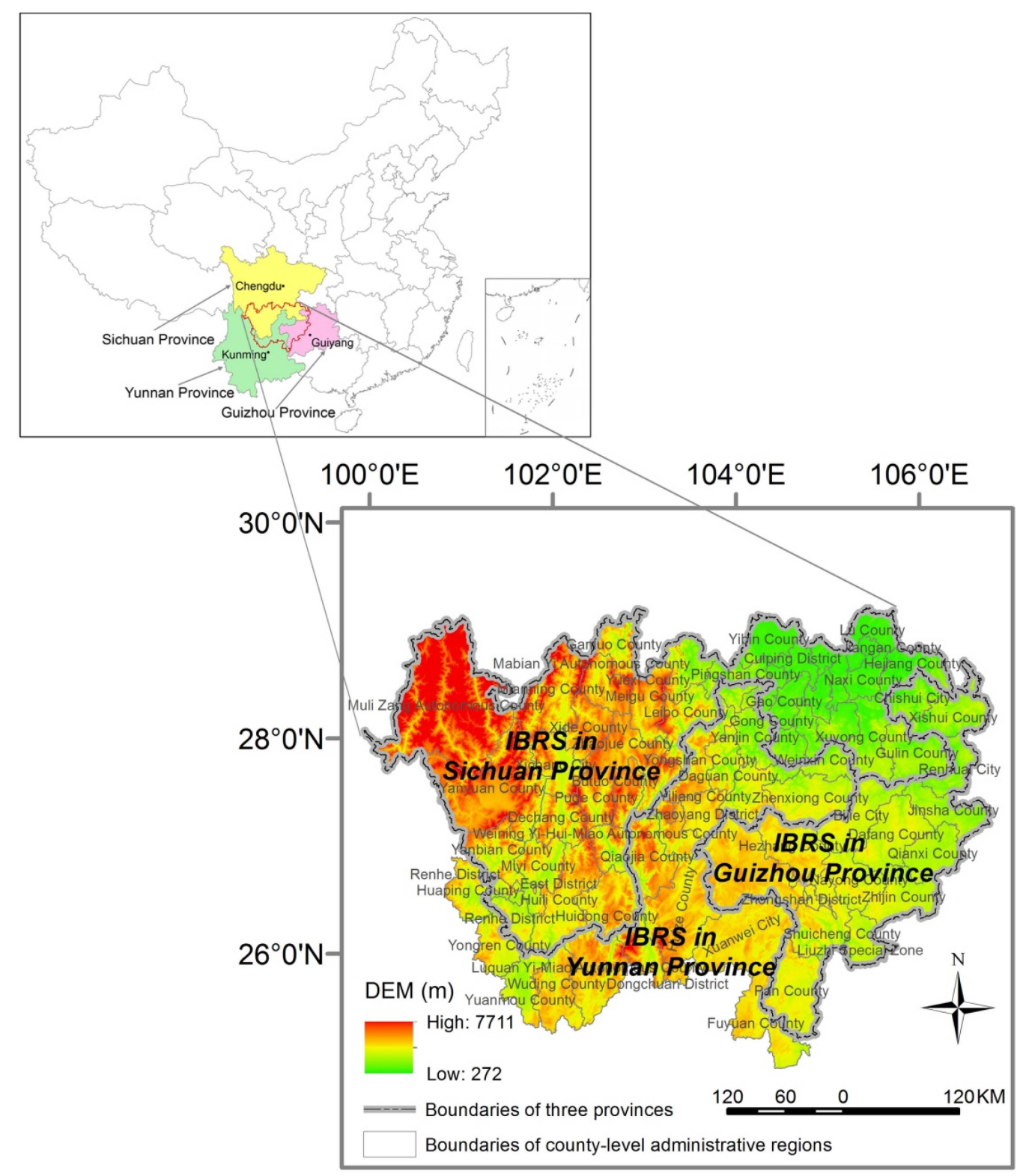

Figure 1. Location and elevation of the study area, the IBRS. 
Table 1. Administrative regions of the IBRS.

\begin{tabular}{|c|c|c|}
\hline Provinces & Prefectures/Cities & Counties \\
\hline \multirow{5}{*}{$\begin{array}{l}\text { Sichuan } \\
\text { Province }\end{array}$} & $\begin{array}{l}\text { Panzhihua City } \\
\text { (totally located in the IBRS) }\end{array}$ & $\begin{array}{l}\text { East District, West District, Renhe District, Miyi County, } \\
\text { Yanbian County } \\
\text { (number: 5) }\end{array}$ \\
\hline & $\begin{array}{l}\text { Luzhou City } \\
\text { (totally located in the IBRS) }\end{array}$ & $\begin{array}{l}\text { Jiangyang District, Naxi County, Longmatan District, Lu } \\
\text { County, Hejiang County, Xuyong County, Gulin County } \\
\text { (number: 7) }\end{array}$ \\
\hline & $\begin{array}{l}\text { Leshan City } \\
\text { (partially located in the IBRS) }\end{array}$ & $\begin{array}{l}\text { Mabian Yi Autonomous County } \\
\text { (mumber: 1) }\end{array}$ \\
\hline & $\begin{array}{l}\text { Yibin City } \\
\text { (totally located in the IBRS) }\end{array}$ & $\begin{array}{l}\text { Cuiping District, Yibin County, Nanxi County, Jiangan } \\
\text { County, Changning County, Gao County, Gong County, } \\
\text { Junlian County, Xingwen County, Pingshan County } \\
\text { (number: 10) }\end{array}$ \\
\hline & $\begin{array}{l}\text { Liangshan Yi Autonomous } \\
\text { Prefecture } \\
\text { (totally located in the IBRS) }\end{array}$ & $\begin{array}{l}\text { Xichang City, Muli Zang Autonomous County, Yanyuan } \\
\text { County, Dechang County, Huili County, Huidong County, } \\
\text { Ningnan County, Puge County, Butuo County, Jinyang } \\
\text { County, Zhaojue County, Xide County, Mianning County, } \\
\text { Yuexi County, Ganluo County, Meigu County, Leibo County } \\
\text { (number: 17) }\end{array}$ \\
\hline \multirow{5}{*}{$\begin{array}{l}\text { Yunan } \\
\text { Province }\end{array}$} & $\begin{array}{l}\text { Kunming City } \\
\text { (partially located in the IBRS ) }\end{array}$ & $\begin{array}{l}\text { Dongchuan District, Luquan Yi-Miao Autonomous County } \\
\text { (number: 2) }\end{array}$ \\
\hline & $\begin{array}{l}\text { Qujing City } \\
\text { (partially located in the IBRS) }\end{array}$ & $\begin{array}{l}\text { Fuyuan County, Huize County, Xuanwei City } \\
\text { (number: 3) }\end{array}$ \\
\hline & $\begin{array}{l}\text { Zhaotong City } \\
\text { (totally located in the IBRS) }\end{array}$ & $\begin{array}{l}\text { Zhaoyang District, Ludian County, Qiaojia County, Yanjin } \\
\text { County, Daguan County, Yongshan County, Suijiang County, } \\
\text { Zhenxiong County, Yiliang County, Weinxin County, } \\
\text { Shuifu County } \\
\text { (number: 11) }\end{array}$ \\
\hline & $\begin{array}{l}\text { Lijiang City } \\
\text { (partially located in the IBRS) }\end{array}$ & $\begin{array}{l}\text { Huaping County } \\
\text { (number: 1) }\end{array}$ \\
\hline & $\begin{array}{l}\text { Chuxiong Autonomous } \\
\text { Prefecture } \\
\text { (partially located in the IBRS) }\end{array}$ & $\begin{array}{l}\text { Yongren County, Yuanmou County, Wuding County } \\
\text { (number: 3) }\end{array}$ \\
\hline \multirow{3}{*}{$\begin{array}{l}\text { Guizhou } \\
\text { Province }\end{array}$} & $\begin{array}{l}\text { Liupanshui City } \\
\text { (totally located in the IBRS) }\end{array}$ & $\begin{array}{l}\text { Zhongshan District, Liuzhi Special Zone, Shuicheng County, } \\
\text { Pan County } \\
\text { (number: } 4 \text { ) }\end{array}$ \\
\hline & $\begin{array}{l}\text { Zunyi City } \\
\text { (partially located in the IBRS) }\end{array}$ & $\begin{array}{l}\text { Xishui County, Chishui City, Renhuai City } \\
\text { (number: 3) }\end{array}$ \\
\hline & $\begin{array}{l}\text { Bijie City } \\
\text { (totally located in the IBRS) }\end{array}$ & $\begin{array}{l}\text { Bijie City, Dafang County, Qianxi County, Jinsha County, } \\
\text { Zhijin City, Nayong County, Weining Yi-Hui-Miao } \\
\text { Autonomous County, Hezhang County } \\
\text { (number: 8) }\end{array}$ \\
\hline
\end{tabular}

\subsection{Data}

Data for this study mainly includes GDP per capita (comparable price), boundary (shapefile format) and digital elevation model (DEM). According to [50], county economy plays an important role in the government's decision-making and macro-control. Taking into account the analysis scale and the accessibility of data, we made use of county-level data to conduct the research. GDP per capita for each county in the years 1995, 2000, 2005 and 2010 were obtained primarily from Sichuan Statistical Yearbook [55-58], Yunnan Statistical Yearbook [59-62] and Guizhou Statistical Yearbook [63-66]. Boundary information and DEM with resolution of $90 \mathrm{~m}$ were got from National Geomatics Center of China. 


\subsection{Methodology}

Although the IBRS is one of the most under-developed areas and one of the poverty alleviation target areas in China, it has experienced relatively rapid economic development and is facing internal regional inequality. Previous studies have revealed that the regional economic development disparities of China are sensitive to geographical scales and significantly affected by globalization, marketization and decentralization [67]. Exploring the multiscale spatio-temporal dynamics of economic development could provide helpful evidence for understanding the IBRS's reality and problems. In view of the deficiency in the small-scale regions and comparative study of multiple scales, we put forward a framework for a multiscale study on economic development dynamics for the IBRS (Figure 2). According to the framework, the Theil index is utilized to analyze the scale effect of economic disparities, while a Markov chain is used for disclosing its spatio-temporal transition features. Besides, the ESDA method (Moran's I, LISA, $G_{i}^{*}$ ) is applied to explore spatial concentration dynamics of economic development.

In consideration of the administrative regions in the IBRS, the county level, prefecture level and region level are deemed to be three spatial scales on which the multiscale analysis of economic disparities is conducted. It should be noted that the province-level scale only refers to the area which respectively belongs to the three provinces of the IBRS. As for prefecture-level scale, there are seven cities totally located in the IBRS, while there are six cities partially located in the IBRS and two of them (Leshan and Lijiang) are screened out. Hence, eleven cities are selected for the prefecture-level analysis.

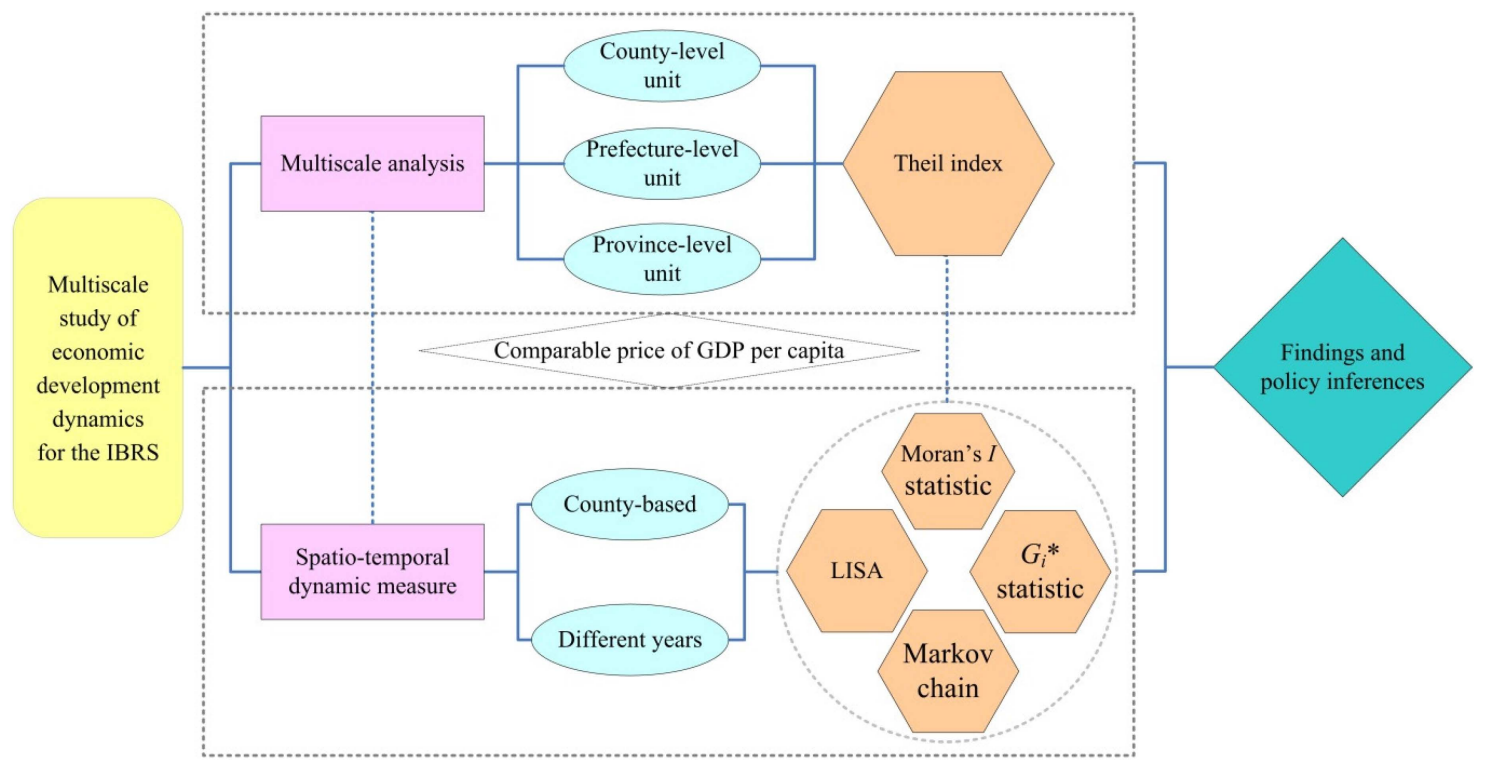

Figure 2. Framework of multiscale study on economic development dynamics for the IBRS.

\subsubsection{Theil Index}

The Theil index is a commonly used method for analyzing regional economic disparities. Its advantage lies in considering the effect of demographic change. In this paper, Theil index was applied to characterize economic disparities among different scales in the IBRS. Theil index is written in the following way [68]:

$$
T=\frac{1}{n} \sum_{i=1}^{n}\left\{\frac{y_{i}}{\bar{y}} \log \left(\frac{y_{i}}{\bar{y}}\right)\right\}
$$

where $T$ is the Theil index, $n$ the unit number corresponding to the selected scale, $y_{i}$ the GDP per capita of unit $i$, and $\bar{y}$ the GDP per capita of all units in the selected scale. According to Formula (1), the degree of economic disparity is positive correlated with the value of $T$, and vice versa. 


\subsubsection{Markov Chain}

The Theil index can describe the dynamic trends of regional economic disparities over time, and decomposing the index could also explain the contribution of disparities inside each group and among groups to the total disparities. However, the distribution pattern evolution of the disparities could not be displayed by the Theil index. Therefore, we employ a Markov chain to reveal the evolution of distribution patterns, and test transition probability matrix in in the likelihood process.

The basic purpose of a Markov chain is to predict a future state by means of studying the initial probability of different states and transition probabilities of states to confirm the variation trends [69]. A Markov process is a random process possessing a property characterized as "memorylessness": the probability distribution of the next step depends only on the present state, and has no relation with the sequence of events that preceded it. Markov chains have many applications as statistical models of real-world processes, such as economic inequality change. In this research, we first classify 75 counties of the IBRS into different categories based on the level of their GDP per capita, and examine the transition probabilities in the given period. Next, the state space matrix $F_{t}$ is established to store the GDP per capita at time $t$ (GDP per capita is divided into $K$ categories). Then, the transition probability matrix $M(K \times K$ dimension $)$ is established, where $K$ represents the numbers of all categories, and the element $m(i, j, t)$ of the transition probability matrix means the probability of some county transiting from level $i$ to level $j$ at time $t$. Finally, the probability of the GDP per capita level of some county is expressed as the state probability vector $R\left(K \times 1\right.$ dimension), denoted as $R_{t}=\left[R_{1 t}, R_{2 t}, \ldots, R_{k t}\right]$, the formula is as following:

$$
R_{t+1}=M \times R_{t}
$$

where $M$ is the transition probability matrix with $K \times K$ dimension of one state transiting to another. If the transition probability does not change over time, then

$$
R_{t+p}=M^{p} \times R_{t}
$$

where $p$ indicates the transion steps.

\subsubsection{ESDA Method}

We use computer software packages of ArcGIS 9.0 and OpenGeoDa to conduct an ESDA study. ESDA is a set of techniques used to describe and visualize spatial distributions, identify typical locations or spatial outliers, discover patterns of spatial association, clusters or hot spots, and suggest spatial regimes or other forms of spatial heterogeneity [70]. Spatial autocorrelation refers to the coincidence of value similarity with local similarity [71]. It can be positive (when high values correlate with high neighboring values or when low values correlate with low neighboring values) or negative (spatial outliers for high-low or low-high values).

Global and local spatial autocorrelation analysis is commonly used for spatial dependence and heterogeneity research. Global spatial autocorrelation is a measure of overall clustering and measured here by Moran's I. It is assessed by means of a test of a null hypothesis of random location. Rejection of this null hypothesis suggests a spatial pattern providing more insights into data distribution. For each variable, Moran's I measures the degree of linear association between its value at one location and the spatially weighted average of neighboring values, being written in the following way [72]:

$$
I=\sum_{i=1}^{n} \sum_{j=1}^{n}\left(X_{i}-\bar{X}\right)\left(X_{j}-\bar{X}\right) / S^{2} \sum_{i=1}^{n} \sum_{j=1}^{n} W_{i j}
$$

where

$$
\bar{X}=\frac{1}{n} \sum_{i=1}^{n} X_{i}
$$

and

$$
S^{2}=\sum_{i=1}^{n}\left(X_{i}-\bar{X}\right) / n
$$


In Formula (4), where $n$ is the number of regions (counties in this study), I stands for Moran index of study period, $X_{i}, X_{j}$ are observations of region $i$ and region $j$ respectively, and $W_{i j}$ is the element of the spatial weight matrix $W . W$ contains the information about the relative spatial dependence between the $\mathrm{n}$ regions. The elements $W_{i j}$ on the diagonal are set to zero whereas the elements $W_{i j}$ indicate the way region $i$ is spatially connected to the region $j$. If region $i$ and $j$ are adjacent, then $W_{i j}=1$, otherwise $W_{i j}=0$.

A Moran's I statistic larger (smaller) than the expected value $E(I)$ indicate positive (negative) spatial autocorrelation. Statistical inference is based on the permutation approach with 10,000 permutations [72]. Values of $I$ vary from 1 to -1 , where a value of " 1 " suggests perfect positive spatial autocorrelation (where high values or low values show spatial cluster), a value of " 1 " suggests perfect negative spatial autocorrelation (a checker board pattern), and " 0 " suggests perfect spatial randomness. In addition, standardized statistic $Z(I)$ is often used to test significance level of Moran's $I$, where $\operatorname{Var}(I)$ is the variance of Moran's $I$. When $Z(I)>1.96$, the null hypothesis of spatial randomness or no spatial autocorrelation should be rejected. $E(I)$ and $Z(I)$ are written in the following way:

$$
\begin{gathered}
E(I)=-1 /(n-1) \\
Z(I)=1-E(I) / \sqrt{\operatorname{Var}(I)}
\end{gathered}
$$

Local spatial autocorrelation is used to assess the local structure of spatial autocorrelation. It is analyzed with three tools: the Moran scatter plot, local indicators of spatial association (LISA) [72], and the $G_{i}{ }^{*}$ statistics [73]. The Moran scatter plot is for displaying the observations for each region (on the horizontal axis) against the standardized spatial weighted average (average of the neighbors' observations, also called spatial lag) on the vertical axis. The Moran scatter plot is therefore divided into four quadrants corresponding to four types of local spatial association between a region and its neighbors: $\mathrm{HH}$, a region with a high value surrounded by regions with high values (Quadrant I in the upper right); $\mathrm{LH}$, a region with a low value surrounded by regions with high values (Quadrant II in the upper left); LL, a region with a low value surrounded by regions with low values (Quadrant III in the lower left); HL, a region with a high value surrounded by regions with low values (Quadrant IV in the lower right). Quadrants HH and LL (resp. LH and HL) refer to positive (resp. negative) spatial autocorrelation indicating spatial clustering of similar (resp. dissimilar) values. Moreover, the use of standardized variables makes the Moran scatter plot comparable across time [33]. LISA statistics calculated for each observation is to obtain an indication of the extent to which the significant spatial clustering is [74]. The sum of LISAs for all observations is proportional to a global indicator of spatial association. Furthermore, LISA can be visualized as a map and is calculated as following [74]:

$$
I_{i}=z_{i} \sum_{j} w_{i j} z_{j}
$$

In the above formula, $z_{i}$ and $z_{j}$ are the deviation from the sample mean, and $W_{i j}$ having same implication as that of Moran's I's measurement. The $G_{i}^{*}$ statistic, measuring the localized spatial dependence based on either proximity or adjacency with the area divided into $W$ subareas, is used to detect local "pockets" of dependence that may not show up when using global statistics. For each region $i$ and a certain time, it is written as follows [73]:

$$
G_{i}^{*}=\sum_{j=1}^{n} W_{i j} X_{j} / \sum_{j=1}^{n} X_{j}
$$

$W_{i j}$ 's implication is the same as that in the measurement of Moran's I in the above formula. The variable $X$ has a natural origin and is positive. Once standardized, a positive value of $G_{i}^{*}$ indicates a spatial cluster of high values, whereas a negative value indicates clustering of low values around region $i$. When $G_{i}{ }^{*}$ is positive there is a high rate of cluster in the local neighborhood of $i$. After the four years' $G i^{*}$ statistics being calculated, the spatialization processes can be accomplished by ArcGIS. 
The hot spot evolution graphs will be generated in ArcGIS by dividing the statistics of each year into four grades from high to low by Jenks Natural Breaks method.

\section{Results and Discussion}

\subsection{Results}

\subsubsection{Scale Effect}

By Formula (1), we get the Theil indexes of the province level, prefecture level and county level of the IBRS from 1995 to 2010 (Figure 3). As can be seen from Figure 3, the disparities of economic development show the following features. (1) The average Theil indexes of province-level units, prefecture-level units and county-level units are 0.047, 0.191 and 0.259 , respectively. This means that the economic disparities are closely related with geographical scales, and the smaller the geographical scale, the bigger the disparity; (2) The disparity over time of the three level units shows an approximately similar reducing trend. This demonstrates that the economic inequality inside the IBRS is gradually weakened during the development process; (3) The dynamic trends of the countyand prefecture-level units are simultaneous. Nevertheless, the disparity of province-level units over the past 16 years keeps rather steady with the Theil index around 0.0500 , which presents some kind of lock-in effect during their economic development over time. On one hand, county- and city-level units play leading roles in economic development over the years, which have relieved the inequality inside the whole region. On the other hand, with the homogeneity of quite low level development, it is difficult to promote economic development effectively only depending on different provincial regions themselves in the IBRS.

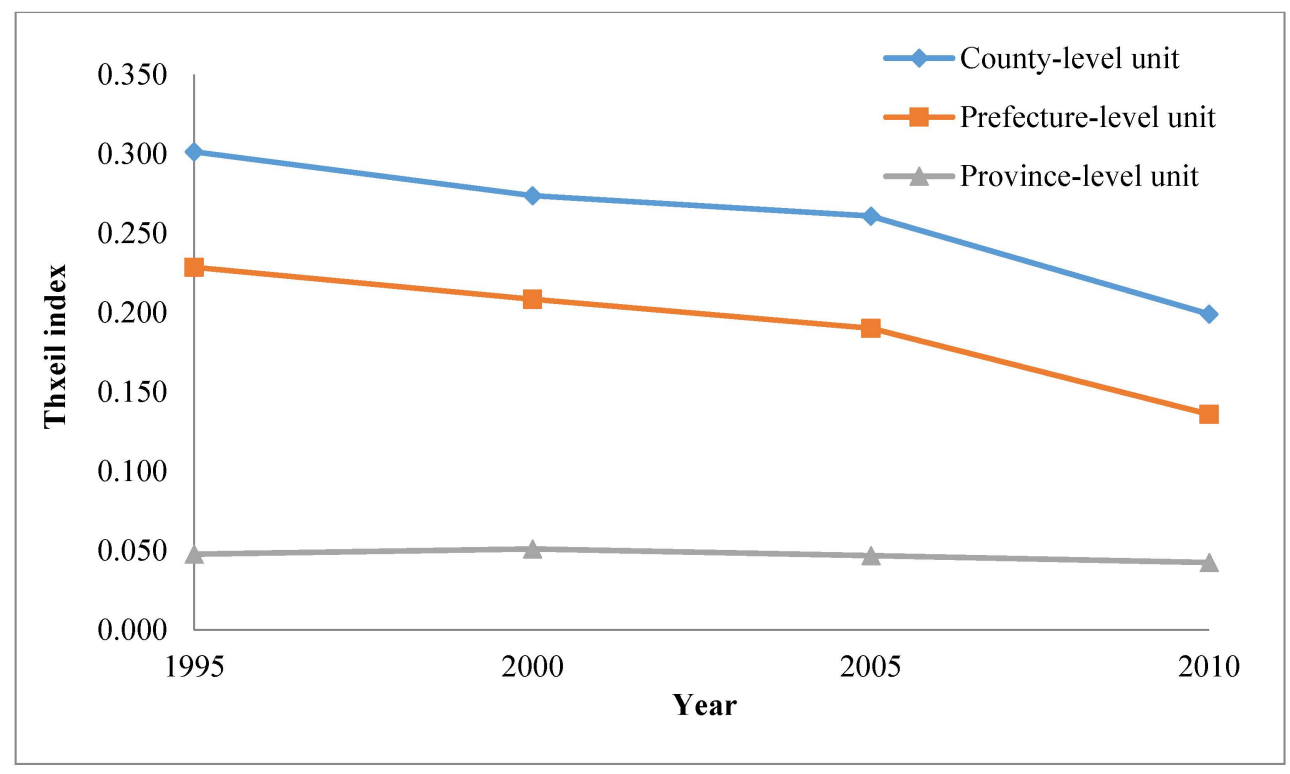

Figure 3. Economic development disparities at different scales of the IBRS from 1995 to 2010.

\subsubsection{Spatio-Temporal Transition}

In order to reveal the spatio-temporal transition of economic disparities in the IBRS, we employ Markov chain analysis. The quartile classification (without regard for year) method is used to divide the GDP per capita of all the counties over the 16 years into four categories: low, relatively low, relatively high, high, and respectively named type 1 , type 2 , type 3 , type 4 . The quartiles are $\$ 272.09$, $\$ 555.93$ and $\$ 1,299.47$. It should be noted that the four-type of GDP per capita is just an internal category for the sake of our analysis, so it does not mean a county is really "high" or "relatively high" in GDP per capita over the country (in 2010, GDP per capital of China was \$4,479). The Markov-chain 
transition matrices of GDP per capita (Table 2) and the spatial distribution of GDP per capita level (Figure 4) are obtained based on Formulas (2) and (3). As seen from Table 2, we can find that all of the transitions are one way along the route "low"-"relatively low"-"relatively high"-"high", skipping one or two grades. It means that the economic development is continuously dynamic and promoted. The detailed transition forms differ greatly over time. From 1995 to 2005, the transitions follow a one-dimensional linear trend, following the route "low"-“relatively low"--"relatively high"-“high". From 2005 to 2010, the skipping (one or two grads) transitions become common, which shows that the economic dynamic degree increases over time. From 1995 to 2010, according to Table 2 and Figure 4, the central and south part of the IBRS are always located by type 1, type 2 or type 3 counties, which have become the most underdeveloped region of the IBRS. A poverty trap is being formed in the central and south part of the IBRS.

Table 2. Markov-chain transition matrices of GDP per capita in the IBRS from 1995 to 2010.

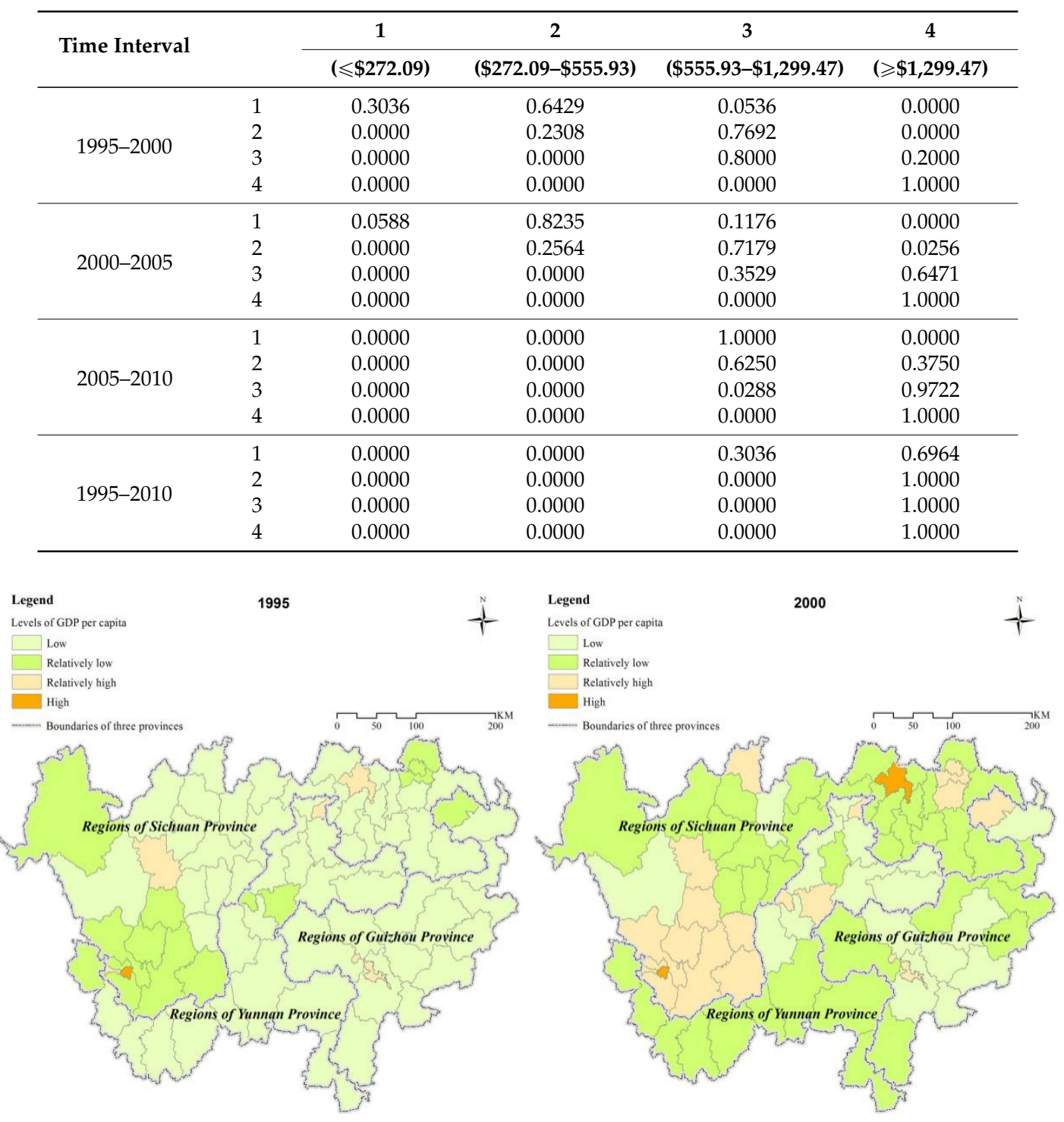

Figure 4. Cont. 

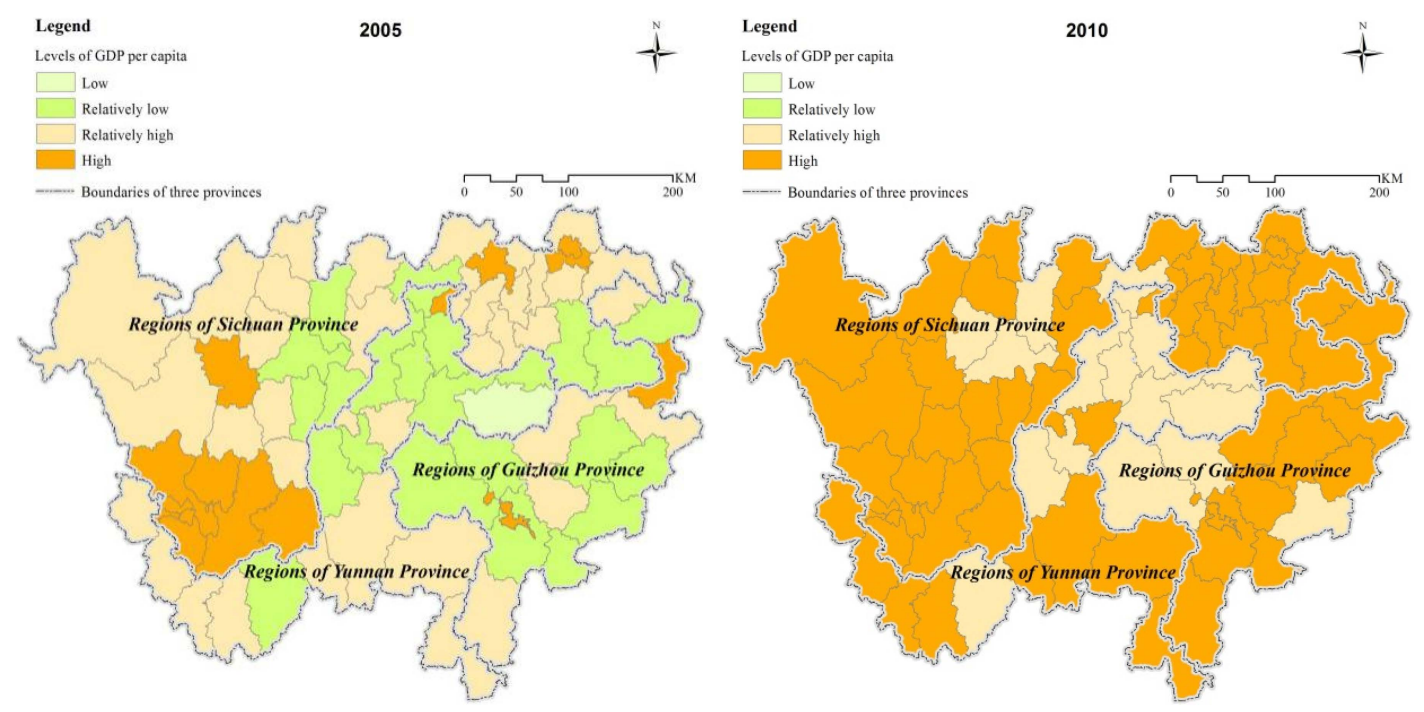

Figure 4. Spatial distribution of GDP per capita level in the IBRS from 1995 to 2010.

\subsubsection{Spatio-Temporal Correlation}

ESDA method is applied to further investigate the spatio-temporal correlation and clustering features of economic development in the IBRS. Taking GDP per capita of 75 county-level region as observations, and using their queen contiguity spatial weight matrix, we get values of the Moran's $I$ statistic (Table 3). Ranging from 0.2588 to 0.4114 during the study period, the statistics indicate positive clustering and the presence of strong positive spatial autocorrelation $(p<0.001, Z(I)>1.96)$. The statistics increase over the whole period, especially from 2005 to 2010, suggesting that the hypothesis of spatial randomness can be rejected and the distribution of regional GDP per capita is a nature clustering. To put it in another way, the regions with relatively high GDP per capita (respectively low) have a propensity to cluster closely more often than if this localization is purely random. It also indicates that the degree of economic polarization has been weakening in the past 16 years.

Table 3. Global Moran's I statistics for GDP per capita in the IBRS from 1995 to 2010.

\begin{tabular}{cccccc}
\hline Year & Moran's $\boldsymbol{I}$ & $\boldsymbol{E}(\boldsymbol{I})$ & Mean & $\boldsymbol{Z}(\boldsymbol{I})$ & $\boldsymbol{p}$ \\
\hline 1995 & 0.3675 & -0.0135 & -0.0151 & 6.245902 & 0.001 \\
2000 & 0.2588 & -0.0135 & -0.0117 & 4.176380 & 0.001 \\
2005 & 0.3097 & -0.0135 & -0.0111 & 4.164948 & 0.001 \\
2010 & 0.4114 & -0.0135 & -0.0138 & 5.371681 & 0.001 \\
\hline
\end{tabular}

Figure 5 displays the Moran scatter plot of regional GDP per capita for 1995, 2000, 2005 and 2010. In the past few years, positive spatial autocorrelation has also been reflected by the slope of the regression lines. Table 4 shows that the major type of spatial distribution is an LL cluster, suggesting that the overall economic development is at a low level balanced state. Scatter plots distributed in the other three quadrants are lower and rather discrete, which means that regions with positive $(\mathrm{HH}$, LL) and negative spatial autocorrelation (HL, LH) are small in number, and the disparities are big among them. It is also obvious that the agglomeration and the diffusion effects of economy are not very strong. Also, the degree of dispersion of data points in each quadrant is increasing especially in Quadrant. Furthermore, the number of $\mathrm{HH}$ regions increases and the number of LL regions decreases, illustrating that the agglomeration effect is strengthening. 

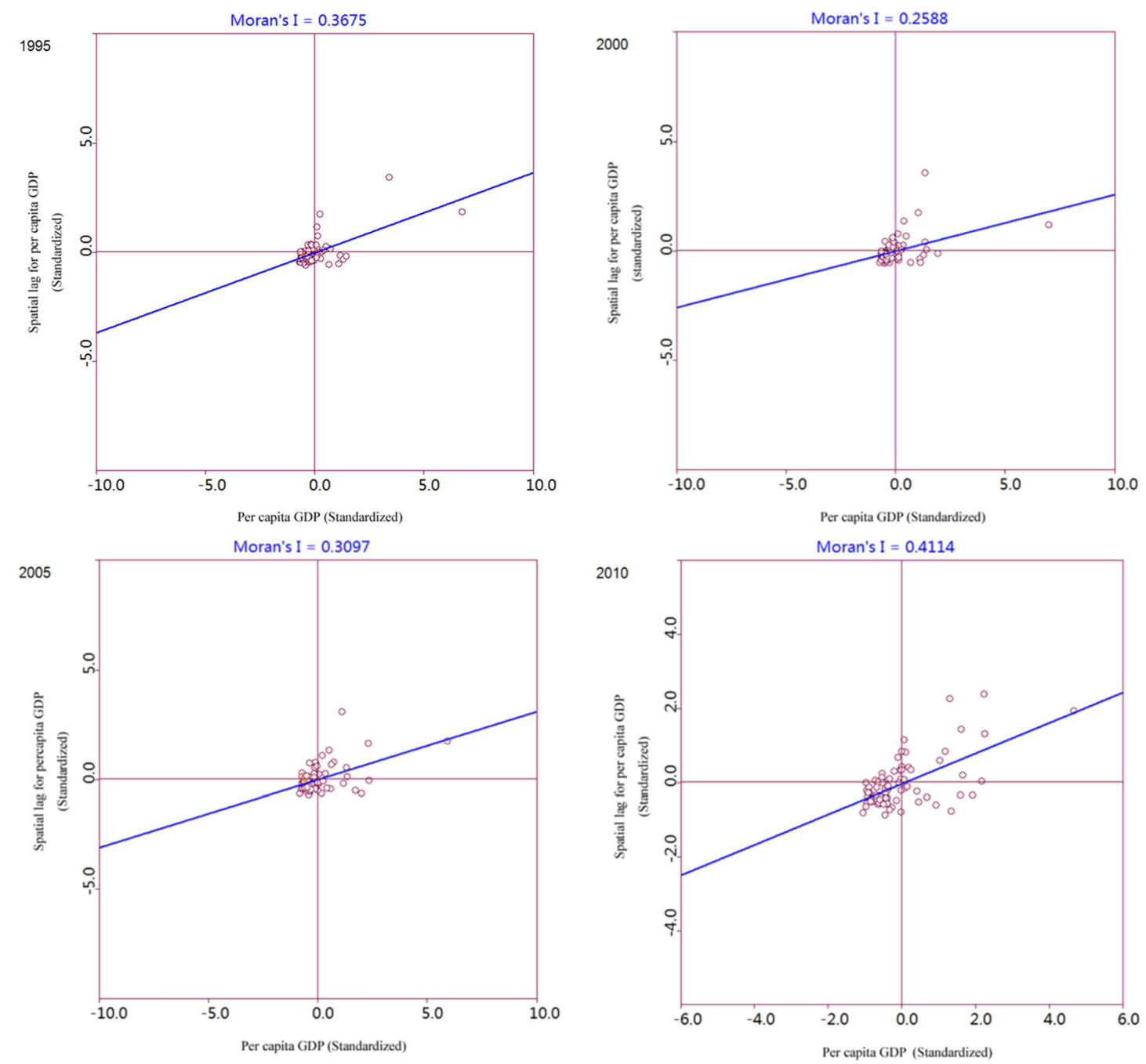

Figure 5. Moran scatter plot for GDP per capita in the IBRS from 1995 to 2010.

Table 4. Number of spatial cluster type for GDP per capita in the IBRS from 1995 to 2010.

\begin{tabular}{ccccccccc}
\hline \multirow{2}{*}{ Types } & \multicolumn{2}{c}{1995} & \multicolumn{2}{c}{$\mathbf{2 0 0 0}$} & \multicolumn{2}{c}{$\mathbf{2 0 0 5}$} & \multicolumn{2}{c}{$\mathbf{2 0 1 0}$} \\
\cline { 2 - 8 } & $\boldsymbol{p}$ = Any & $\boldsymbol{p}<\mathbf{0 . 0 5}$ & $\boldsymbol{p}$ = Any & $\boldsymbol{p}<\mathbf{0 . 0 5}$ & $\boldsymbol{p}$ = Any & $\boldsymbol{p}<\mathbf{0 . 0 5}$ & $\boldsymbol{p}=$ Any & $\boldsymbol{p}<\mathbf{0 . 0 5}$ \\
\hline HH & 11 & 3 & 11 & 3 & 13 & 3 & 15 & 5 \\
LH & 13 & 0 & 12 & 0 & 13 & 0 & 13 & 0 \\
LL & 42 & 9 & 41 & 6 & 40 & 8 & 39 & 8 \\
HL & 9 & 4 & 11 & 5 & 9 & 4 & 8 & 3 \\
\hline
\end{tabular}

LISA is another method to detect local spatial clusters but also to analyze local instability in the form of atypical localizations, spatial outliers and spatial regimes. The cluster maps for GDP per capita shown in Figure 6 provide evidence of spatial clustering in geographical space. The maps were generated based on 999 permutations with a significance filter of 0.05 . As can be seen from Table 4 and Figure 6, there are only three significant spatial cluster types in our study: HH, LL, and HL. In the four time points, the number of regions showing significant local Moran's statistics are 16 with a proportion of $21.3 \%, 15$ with a proportion of $20.0 \%, 14$ with a proportion of $18.6 \%$ and 16 with proportion of $21.3 \%$. It indicates that the degree of spatial cluster of GDP per capita remained relatively stable in the study period. Otherwise, the regions with not significant local Moran's statistics take up nearly $80 \%$ of the total number, illustrating that low level of economic development dominated in the study 
area. Furthermore, HH, LL, and HL regions presented different spatial variation from 1995-2010. For HH regions, their number and spatial distribution did not change until 2010. In 2010, Huili County, Liangshan Yi Autonomous Prefecture of Sichuan Province and Huaping County, Lijiang City of Yunnan Province became an HH region. Before that, the HH regions including Yanbian County, West District and East District, remained in the Panzhihua City of Sichuan Province. As for LL regions, although in 1995 they were mainly concentrated in the north and east of the IBRS belonging to Liangshan Yi Autonomous Prefecture of Sichuan Province, Bijie Prefecture of Guizhou province and Zhaotong City of Yunnan Province, all of them moved to the north center belonging to Liangshan Yi Autonomous Prefecture and Zhaotong City in 2010. Although the number of significant HH regions is still less than that of significant LL regions, the gap between them is narrowing. Moreover, $\mathrm{HH}$ regions take on concentrating and growing tendency with the passage of time. However, for HL regions, the number as well as spatial distribution is shrinking. Thus, the tendency toward spatial clustering in the IBRS is increasing over time.
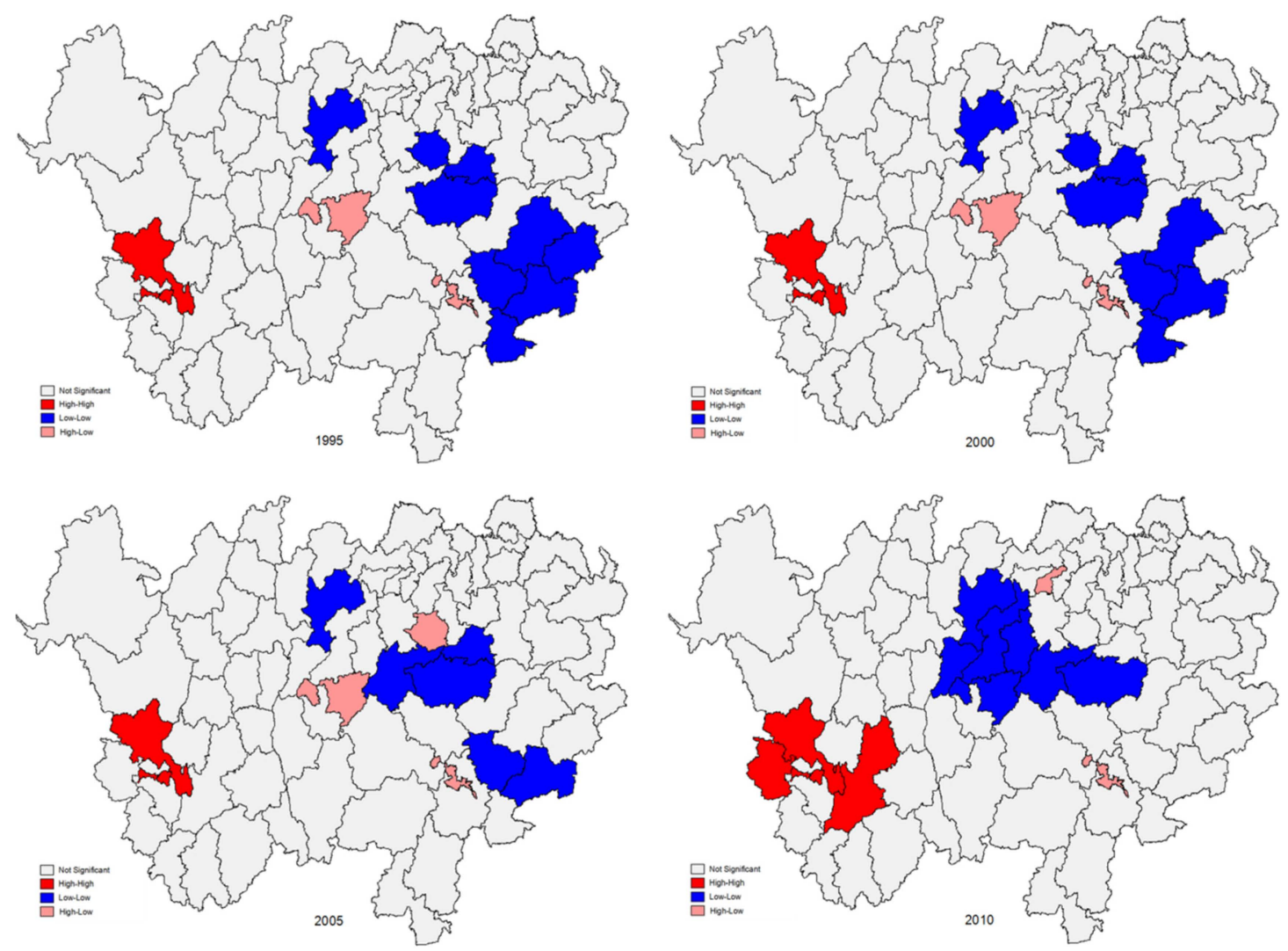

Figure 6. LISA cluster map for GDP per capita in the IBRS (5\% pseudo-significance level) from 1995 to 2010.

In order to effectively understand the dynamic process of the economic spatial pattern, it is necessary to explore the change of hot spot clustering. From Figure 7, the overall distribution of hot spot zones remains relative stable, with high value (hot spot and sub-hot spot) clustering in the small area of west and northeast, and low value (cold spot and sub-cold spot) clustering in the large area of northwest, east and central part. Economic hot spot evolution features of the IBRS were summarized based on the changes in number and spatial structure. 


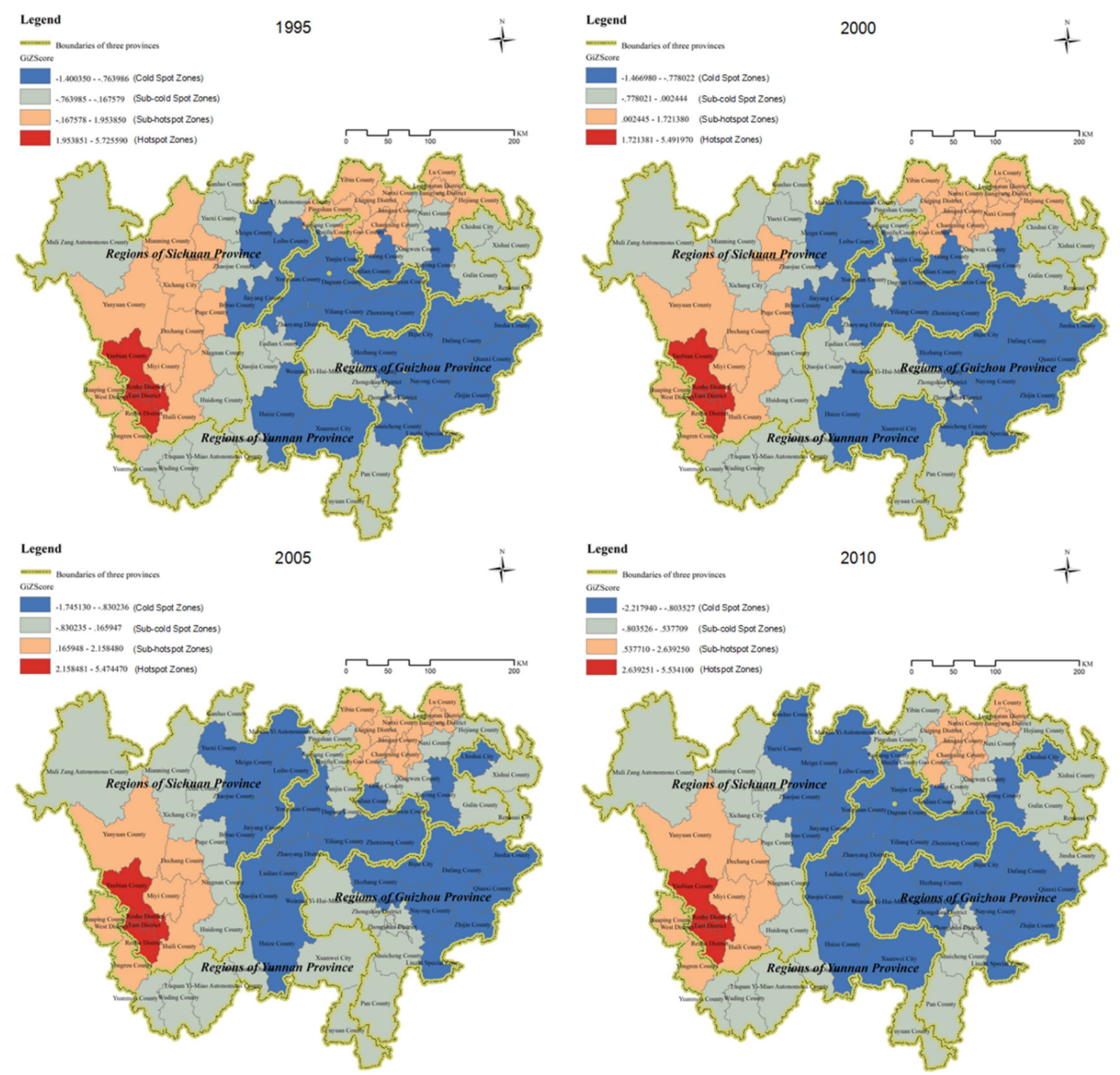

Figure 7. Spatial pattern evolution of economic hot spots in the IBRS from 1995 to 2010.

In terms of number, the number of hot spots and sub-hot spots (high value clustering) decreases but that of cold spots and sub-cold spots (low value clustering) increases. The proportion of high value clustering declined from $33.33 \%$ to $25.33 \%$, with that of low value clustering climbing from $66.67 \%$ to $74.67 \%$. Despite the economic core not changing over the time, sub-hot spots decline in number. Meanwhile, cold spots' proportion increases to $40 \%$ and that of sub-cold spots first increases and then decreases to $34.67 \%$.

In terms of spatial structure, an approximate circle structure with two cores in the southwest and northeast is shaped by cold spots and sub-cold spots gathering together respectively, while the range of hot spot and sub-hot shrink over time (Figure 8). Specifically, sub-hot spots (if any), sub-cold spots and cold spots surround the two cores sequentially from the inner to the outer. The cold spots, between the two cores, tend to gather into a mass and seems to be a boundary of the two circles. Moreover, the southwest core located in Panxi region of Sichuan Province is always the hot spot of the IBRS, with the northeast core located in Hilly Sichuan Basin of southeast Sichuan. However, the broad area in the east and central, such as most of Zhaotong City, Bijie Prefecture, Da\&Xiao Liangshan (one of China's poorest regions) and Qujing City are almost always in the cold spot of low level of development in the study period. 


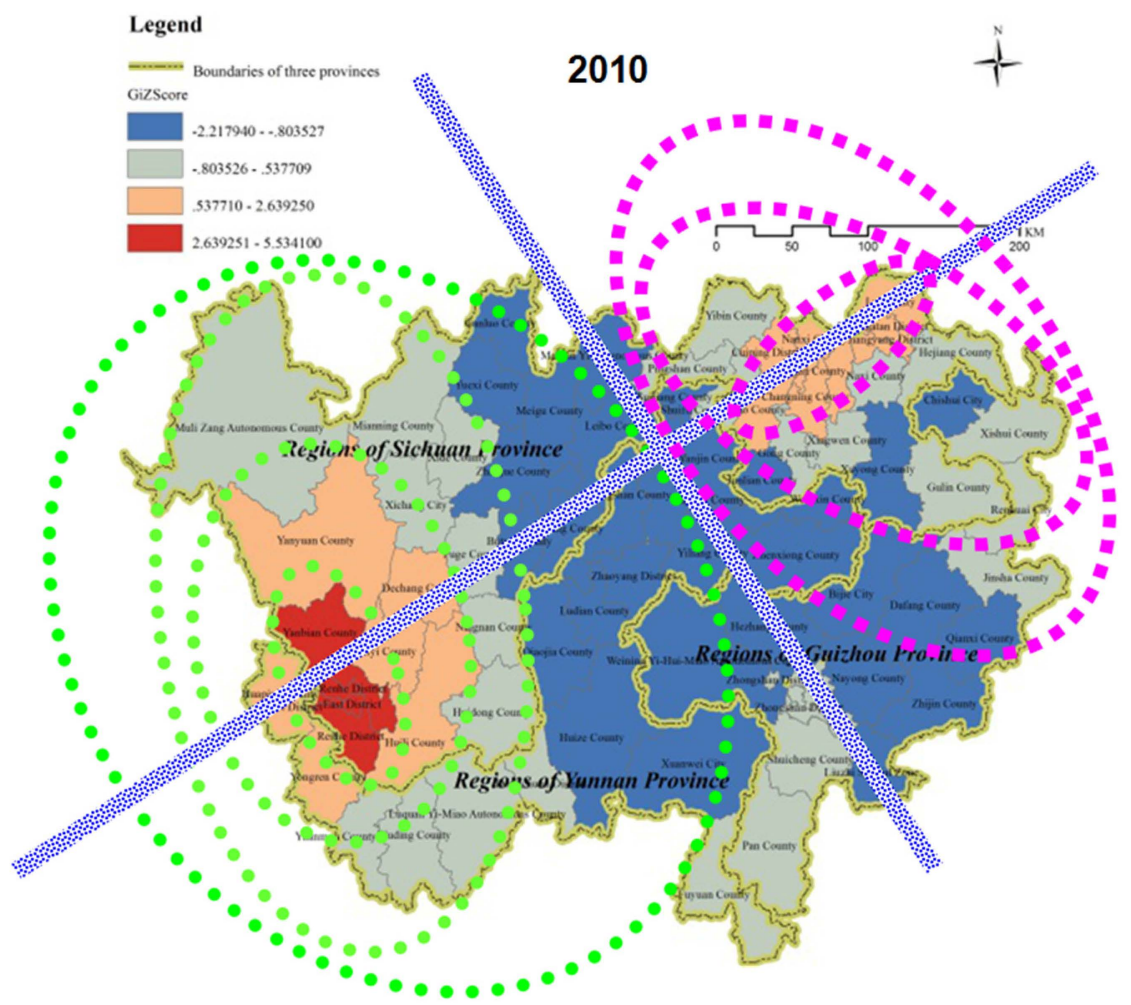

Figure 8. Circle structure of economic development in the IBRS in 2010.

\subsection{Discussion}

The analysis framework that is put forward in this paper helps us to figure out the disparity scale effect, spatio-temporal transition, spatio-temporal correlation and clustering of economic development dynamics in the IBRS over 16 years. Since the socialist market reform was implemented in 1990, China's accession to WTO and "Western Development Strategy" carried out in 2000, the overall gaps among regions (counties) of the IBRS had been narrowed according to Theil index. The positive clustering and the presence of strong positive spatial autocorrelation is founded in the whole IBRS. However, the poverty trap is shown being formed central and southern with low level of economic development dominated in other parts of the IBRS.

There are three reasons for the above phenomenon. The first basic reason lies in remoteness and isolation by virtue of geographical conditions and location. These two factors played fundamental and long-term roles in the development of a mountain area. Figures 1, 4 and 7 provide evidence that both of the economic development cores are located in the places with relatively low elevation. The second reason was the barrier effect of the administrative boundary. From the scale effect and spatio-temporal correlation, the lock in effect of province-level economy and the hot spot remaining in certain areas with other regions are proved to exist. Moreover, the "approximate circle structure with sub-hot spot (if any), sub-cold spot and cold spot surrounding two cores sequentially from the inner to the outer" coincides well with the location of provincial boundaries in the IBRS. The range of cold spots also seems to be increasing in the central part, composed by part of Sichuan-Yunnan IBR and part of Yunan-Guizhou IBR. Last but not least, the lack of effective growth poles in the IBR of Yunnan and Guizhou is another important reason. In the context of the barrier effect from the administrative boundary, economic polarization weakening and even lacking effective growth poles increase the difficulty of obtaining good development opportunities for underdeveloped regions in the Yunan-Guizhou IBR. Then again, strengthening provincial planning and implementation for the Yangtze River Economic Belt has been realized by the central government [75]. Under the circumstances, there is no reason not to intensify cooperation among the three provinces of the IBRS, which is an important part of the upper reaches of 
the Yangtze River economic belt. Therefore, besides developing transportation and other infrastructure, breaking down the rigid shackles on administrative districts for trans-provincial cooperation, and promoting growth poles in line with local conditions in the Yunnan-Guizhou IBR may be more important for the study area to achieve a high level of balanced development in the future.

Compared with the previous study [76], this research not only finds that the economic disparity of the IBRS has been decreasing over the past 16 years along with the disparity scale effect, but also visually illustrated the main causes for the entire low level of balanced development with the spatial pattern evolution of economic hot spots. Therefore, this study may provide more convincing evidence for the policy recommendations.

In addition, it should be noted that although GDP per capita is the main indicator to measure economic development, China's GDP accounting started in 1985 and the accounting methods of county-level administrative regions were not uniform, which resulted in difficulty in data collection, especially in 1995. For instance, the difference in standard of population statistics (registered permanent residence or resident population) in 1995 would impact data accuracy. Nevertheless, the main purpose of our study is to explore the dynamic trend and disparity of economic development. Consequently, those data quality issues could hardly produce effects on the research results.

\section{Conclusions}

Based on the framework of a multiscale study on economic development dynamics, this article analyzed the disparity scale effect, spatio-temporal transition, spatio-temporal correlation and clustering pattern of economic development from 1995 to 2010, as well as the implication for regional development in the IBRS. A quantitative study on county GDP per capita was conducted using Theil index, Markov chain, GIS and ESDA methods. We came to the following conclusions:

(1) Multiscale Theil index analysis showed that the economic disparity was closely related with geographical unit scale in the IBRS; the smaller the unit, the bigger the disparity. The decreasing trend of disparity over time demonstrated economic inequality gradually weakened by county- and city-level units' development.

(2) ESDA indicated that the economic development of the IBRS over time presented significant positive spatial autocorrelation with some stability in space and apparently increasing, as well as the degree of economic polarization weakening. Furthermore, an approximate circle structure with two cores of southwest and northeast had been formed in the IBRS economic map. The Panxi region as the southwest core and a part of Hilly Sichuan Basin as the northeast core kept to be the highlands of economic development.

(3) Most IBRS regions in the east and central region, however, were almost always located in the cold spot zones with a low level of development in the study period. In addition, a poverty trap is being formed in the central and south part of the IBRS.

(4) Geographical conditions and location, the administrative barriers, and the lack of effective growth poles in the Yunnan-Guizhou IBR may be the main causes for the entire low level of balanced development.

(5) Compared with developing transportation and other infrastructure, breaking down the rigid shackles of administrative districts on trans-provincial cooperation, as well promoting growth poles in the Yunnan-Guizhou IBR may carry great significance for the study area in order to achieve a high level of balanced development in the future.

Acknowledgments: We would like to thank the three reviewers and Dr. Anne Zimmermann for their constructive comments and suggestions. This research was supported by the National Basic Research Program of China (No. 2015CB452706), the National Natural Science Foundation of China (No. 41301193), and the Knowledge Innovation Program of Chinese Academy of Sciences (Grant No. KZCX2-YW-333, KZCX2-EW-317).

Author Contributions: Jifei Zhang and and Wei Deng conceived and designed the research; Jifei Zhang collected and processed the data; Jifei Zhang analyzed the data. All authors have read and approved the final manuscript.

Conflicts of Interest: The authors declare no conflict of interest. 


\section{References}

1. World Bank. China Overview. 2015. Available online: www.worldbank.org/en/country/china/overview (accessed on 8 December 2015).

2. Cai, F.; Wang, D.W.; Du, Y. Regional disparity and economic growth in China: The impact of labor market distortions. China Econ. Rev. 2002, 13, 197-212.

3. Jones, D.C.; Li, C.; Owen, A.L. Growth and regional inequality in China during the reform era. China Econ. Rev. 2003, 14, 186-200. [CrossRef]

4. Chen, M.J.; Zheng, Y.N. China's regional disparity and its policy responses. China World Econ. 2008, 16, 16-32. [CrossRef]

5. Demurger, S. Infrastructure development and economic growth: An explanation for regional disparities in China. J. Comp. Econ. 2001, 29, 95-117. [CrossRef]

6. Xu, J.H.; Lu, Y.; Su, F.L.; Ai, N.S. R/S and wavelet analysis on evolutionary process of regional economic disparity in China during past 50 years. Chin. Geogr. Sci. 2004, 14, 193-201. [CrossRef]

7. Lu, W.M.; Lo, S.F. A closer look at the economic-environmental disparities for regional development in China. Eur. J. Oper. Res. 2007, 183, 882-894. [CrossRef]

8. Lessmann, C. Foreign direct investment and regional inequality: A panel data analysis. China Econ. Rev. 2013, 24, 129-149. [CrossRef]

9. Pao, H.T.; Tsai, C.M. Modeling and forecasting the $\mathrm{CO}_{2}$ emissions, energy consumption, and economic growth in Brazil. Energy 2011, 36, 2450-2458. [CrossRef]

10. Nichols, A. Income inequality, volatility, and mobility risk in China and the US. China Econ. Rev. 2010, 21, S3-S11.

11. Lidia, C.; Paolo, V. The origins of the Gini index: Extracts from Variabilita e Mutabilita (1912) by Corrado Gini. J. Econ. Inequal. 2012, 10, 421-443.

12. Mishra, A.; Ray, R. Prices, Inequality, and poverty: Methodology and Indian evidence. Rev. Income Wealth 2011, 57, 428-448.

13. Duro, J.A.; Padilla, E. Inequality across countries in energy intensities: An analysis of the role of energy transformation and final energy consumption. Energy Econ. 2011, 33, 474-479.

14. Martinez, R. Inequality and the new human development index. Appl. Econ. Lett. 2012, 19, 533-535.

15. Dauth, W. Agglomeration and regional employment dynamics. Pap. Reg. Sci. 2013, 92, 419-435. [CrossRef]

16. Wojcik, D. Securitization and its footprint: The rise of the US securities industry centers centers 1998-2007. J. Econ. Geogr. 2011, 11, 925-947. [CrossRef]

17. Gochoco-Bautista, M.S.; Bautista, C.C.; Maligalig, D.S.; Sotocinal, N.R. Income polarization in Asia. Asian Econ. Pap. 2013, 12, 101-136.

18. Wang, Y; Chen, Y.N.; Li, Z. Evolvement characteristics of population and economic gravity centers in Tarim river basin, Uygur Autonomous Region of Xinjiang, China. Chin. Geogr. Sci. 2013, 23, 765-772.

19. Xie, L.N.; Zeng, S.X.; Zou, H.; Tam, V.W.Y.; Wu, Z.H. Technology transfer in clean development mechanism (CDM) projects: Lessons from China. Technol. Econ. Dev. Econ. 2013, 19, S471-S495.

20. Huang, B.; Meng, L.N. Convergence of per capita carbon dioxide emissions in urban China: A spatiotemporal perspective. Appl. Geogr. 2013, 40, 21-29.

21. Unwin, A.; Unwin, D.; Fischer, P. Exploratory spatial data analysis with local statistics. Stat 1998, 47, 415-421.

22. Arbia, G. The role of spatial effects in the empirical analysis of regional concentration. J. Geogr. Syst. 2001, 3, 271-281. [CrossRef]

23. Goodchild, M.F.; Anselin, L.; Appelbaum, R.; Harthorn, B.H. Toward spatially integrated social science. Int. Reg. Sci. Rev. 2000, 23, 139-159.

24. Li, Y.R.; Wei, Y.H.D. The spatial-temporal hierarchy of regional inequality of China. Appl. Geogr. 2010, 30, 303-316.

25. Porter, J.R.; Purser, C.W. Social disorganization, marriage, and reported crime: A spatial econometrics examinations of family formation and criminal offending. J. Crim. Just. 2010, 38, 942-950. [CrossRef]

26. Ye, X.Y.; Wu, L. Analyzing the dynamics of homicide patterns in Chicago: ESDA and spatial panel approaches. Appl. Geogr. 2011, 31, 800-807. [CrossRef]

27. Yao, J.; Murray, A.T.; Agadjanian, V.; Hayford, S.R. Geographic influences on sexual and reproductive health service utilization in rural Mozambique. Appl. Geogr. 2012, 32, 601-607. [CrossRef] [PubMed] 
28. Fritzell, J. Income inequality trends in the 1980s: A five country comparison. Acta Soc. 1993, 36, 47-62. [CrossRef]

29. Fan, C.C. The temporal and spatial dynamics of income and population growth in Ohio, 1950-1990. Reg. Stud. 1994, 28, 241-258. [CrossRef] [PubMed]

30. Fedolov, L. Regional inequality and polarization in Russia. World Dev. 2002, 30, 443-456.

31. Yang, Z.S.; Cai, J.M. Progress of spatial statistics and its application in economic geography. Progr. Geogr. 2010, 29, 757-768. (In Chinese)

32. Gallo, J.L.; Ertur, C. Exploratory spatial data analysis of the distribution of regional per capita GDP in Europe, 1980-1995. Pap. Reg Sci. 2003, 82, 175-201. [CrossRef]

33. Ertur, C.; Koch, W. Regional disparities in the European Union and the enlargement process: An exploratory spatial data analysis, 1995-2000. Ann. Reg. Sci. 2006, 40, 723-765. [CrossRef]

34. Celebioglu, F.; Dall'Erba, S. Spatial disparities across the regions of Turkey: An exploratory spatial data analysis. Ann. Reg. Sci. 2010, 45, 379-400. [CrossRef]

35. Pu, Y.X.; Ge, Y.; Ma, R.H.; Huang, X.Y.; Ma, X.D. Analyzing regional economic disparities based on ESDA. Geogr. Res. 2005, 24, 965-974. (In Chinese)

36. Wu, S.D.; Wang, Q. Regional economic disparities and coordination of economic development in coastal areas of southeastern China, 1995-2005. Acta Geogr. Sin. 2008, 63, 123-134. (In Chinese).

37. Dong, G.P.; Guo, T.Y.; Ma, J. GIS based analysis on spatial disparity of economic growth in Beijing-TianjinHebei Metropolitan Region. J. Geo-inform. Sci. 2010, 12, 797-805. (In Chinese).

38. Xiong, W.; Xu, Y.L.; Wang, Y.Y. Temporal-spatial change of the county-level economic disparities in Jiangsu Province. Progr. Geogr. 2011, 30, 224-230. (In Chinese)

39. Liu, Q.C.; Wang, Z. Research on geographical elements of economic difference in China. Geogr. Res. 2009, 28, 430-440. (In Chinese)

40. Pan, W.Q. The economic disparity between different regions of China and its reduction: An analysis from the geographical perspective. Soc. Sci. China. 2010, 1, 72-84. (In Chinese)

41. Lu, D.D.; Liu, Y.; Fan, J. The regional policy effects and regional development states in China. Acta Geogr. Sin. 1999, 54, 496-508. (In Chinese)

42. Wu, D.T. A study on North-South differences in economic growth. Geogr. Res. 2001, 20, 238-246. (In Chinese)

43. Guo, T.Y.; Xu, Y. The long-term trends of regional economic inequalities in China, 1952-2003. Progr. Geogr. 2005, 24, 21-30. (In Chinese)

44. Ou, X.J.; Shen, Z.P.; Wang, R.C. Spatial structure evolution of regional economic growth and its inequality in China since 1978. Sci. Geogr. Sin. 2006, 26, 641-648. (In Chinese).

45. Villaverde, J.; Maza, A.; Ramasamy, B. Provincial disparities in post-reform China. China World Econ. 2010, 18, 73-95. [CrossRef]

46. Wang, Q.Y.; Xu, X.P. The spatial difference of regional economic develop in Jilin Province. Econ. Geogr. 2008, 28, 25-28. (In Chinese)

47. Qiu, F.D.; Tong, L.J.; Zhu, C.G.; Yang, R.S. Spatio-temporal pattern and driving mechanism of economic development discrepancy in provincial border-regions: A case study of Huaihai economic zone. Geogr. Res. 2009, 28, 451-463. (In Chinese)

48. Guo, R.X. The impact of spatial organizational structures on the economic development of provincial border-regions. Sci. Geogr. Sin. 1993, 13, 197-204. (In Chinese)

49. Yu, F.M.; Zhang, Y.S.; Zhou, D.H.; Du, Z.C. Analyzing provincial border-regional economic disparities based on ESDA and GIS: A case study of Hohhot-Baotou-Ordos-Yulin Economic Zone. Progr. Geogr. 2012, 31, 997-1004. (In Chinese)

50. Chen, P.Y.; Zhu, X.G. Regional inequalities in China at different scales. Acta Geogr. Sin. 2012, 67, $1085-1097$. (In Chinese)

51. Anonymous. Li Urges Building Yangtze River Economic Belt. Available online: http:/ /www.chinadaily. com.cn/business/2014-04/29/content 17472684.htm (accessed on 17 February 2015).

52. Anonymous. China: Yangtze River Economic Zone Proposal. Available online: http://www.gov.uk/ government/publications / china-premier-li-proposes-gigantic-yangtze-river-economic-zone-may-2014/ china-premier-li-proposes-gigantic-yangtze-river-economic-zone-may-2014 (accessed on 17 February 2015).

53. Chen, Z.J. Study on integrated development strategy of the border of Sichuan, Yunnan, and Guizhou Province. Resour. Environ. Yangtza Basin 1994, 3, 193-199. (In Chinese) 
54. Pan, K.W.L.; Wu, N.; Pan, K.Z.; Chen, Q.H. Adiscussion on the issues of the re-construction of ecological shelter zone on the upper reaches of the Yangtze River. Acta Ecol. Sin. 2004, 24, 617-629. (In Chinese).

55. Statistical Bureau of Sichuan, National Bureau of Statistics of China Survey Office in Sichuan. Sichuan Statistical Yearbook 1996; China Statistics Press: Beijing, China, 1996. (In Chinese)

56. Statistical Bureau of Sichuan, National Bureau of Statistics of China Survey Office in Sichuan. Sichuan Statistical Yearbook 2001; China Statistics Press: Beijing, China, 2001. (In Chinese)

57. Statistical Bureau of Sichuan, National Bureau of Statistics of China Survey Office in Sichuan. Sichuan Statistical Yearbook 2006; China Statistics Press: Beijing, China, 2006. (In Chinese)

58. Statistical Bureau of Sichuan, National Bureau of Statistics of China Survey Office in Sichuan. Sichuan Statistical Yearbook 2011; China Statistics Press: Beijing, China, 2011. (In Chinese)

59. Statistical Bureau of Yunnan, National Bureau of Statistics of China Survey Office in Yunnan. Yunnan Statistical Yearbook 1996; China Statistics Press: Beijing, China, 1996. (In Chinese)

60. Statistical Bureau of Yunnan, National Bureau of Statistics of China Survey Office in Yunnan. Yunnan Statistical Yearbook 2001; China Statistics Press: Beijing, China, 2001. (In Chinese)

61. Statistical Bureau of Yunnan, National Bureau of Statistics of China Survey Office in Yunnan. Yunnan Statistical Yearbook 2006; China Statistics Press: Beijing, China, 2006. (In Chinese)

62. Statistical Bureau of Yunnan, National Bureau of Statistics of China Survey Office in Yunnan. Yunnan Statistical Yearbook 2011; China Statistics Press: Beijing, China, 2011. (In Chinese)

63. Statistical Bureau of Guizhou, National Bureau of Statistics of China Survey Office in Guizhou. Guizhou Statistical Yearbook 1996; China Statistics Press: Beijing, China, 1996. (In Chinese)

64. Statistical Bureau of Guizhou, National Bureau of Statistics of China Survey Office in Guizhou. Guizhou Statistical Yearbook 2001; China Statistics Press: Beijing, China, 2001. (In Chinese)

65. Statistical Bureau of Guizhou, National Bureau of Statistics of China Survey Office in Guizhou. Guizhou Statistical Yearbook 2006; China Statistics Press: Beijing, China, 2006. (In Chinese)

66. Statistical Bureau of Guizhou, National Bureau of Statistics of China Survey Office in Guizhou. Guizhou Statistical Yearbook 2011; China Statistics Press: Beijing, China, 2011. (In Chinese)

67. Wei, Y.H.D. Multiscale and multimechanisms of regional inequality in China: Implications forregional policy. J. Contemp. China 2002, 11, 109-124. [CrossRef]

68. Conceição, P.; Ferreira, P. The Young Person's Guide to the Theil Index: Suggesting Intuitive Interpretations and Exploring Analytical Applications. 2000. Available online: http://dx.doi.org/10.2139/ssrn.228703 (accessed on 25 February 2016).

69. Ye, X.Y.; Li, J.J.; Cheng, Y.Q. Multi-scale and multi-mechanism analysis of the spatial pattern and temporal change of regional economic development disparities in Zhejiang Province. Progr. Geogr. 2014, 33, 1177-1186. (In Chinese)

70. Anselin, L. Interactive techniques and exploratory spatial data analysis. In Geographical Information Systems: Principles, Technical Issues, Management Issues and Applications; Longley, P.A., Goodchild, M.F., Maguire, D.J., Rhind, D.W., Eds.; Wiley: Hoboken, NJ, USA, 2005; pp. 253-266.

71. Anselin, L. Spatial Econometrics. In A Companion to Theoretical Econometrics; Baltagi, B.H., Ed.; Blackwell: Oxford, UK, 2001; pp. 310-330.

72. Anselin, L. Local indicators of spatial association LISA. Geogr. Anal. 1995, 27, 93-115. [CrossRef]

73. Getis, A.; Ord, J.K. The analysis of spatial association by use of distance statistics. Geogr. Anal. 1992, 24, 189-206. [CrossRef]

74. Dall'Erba, S. Distribution of regional income and regional funds in Europe 1989-1999: An exploratory spatial data analysis. Ann. Reg. Sci. 2005, 39, 121-148. [CrossRef]

75. Anonymous. China, People's Republic of: Strengthening Provincial Planning and Implementation for the Yangtze River Economic Belt. Available online: http://www.adb.org/zh/node/176121 (accessed on 17 February 2015).

76. Yu, H.; Liu, S.Q.; Guo, S.L.; Zhang, H.Q. Border effect of non-equilibrium economy in contiguous areas of Sichuan, Yunnan and Guizhou Provinces. Urban. Environ. Urban. Ecol. 2011, 24, 29-32.

(C) 2016 by the authors; licensee MDPI, Basel, Switzerland. This article is an open access article distributed under the terms and conditions of the Creative Commons by Attribution (CC-BY) license (http:/ / creativecommons.org/licenses/by/4.0/). 